Endocrinol. Japon. 1968, 15 (3), 291 297

\title{
THE ALTERATION OF ISOZYMIC PATTERNS IN LACTATE DEHYDRO- GENASE DURING ARTIFICIAL MATURATION OF RAT OVARY
}

\author{
ToKiniro MATSUZAWA AND HIROO TAKIKAWA \\ Department of Pharmaceutical Chemistry, Institute of Endocrinology, \\ Gunma University, Maebashi
}

\begin{abstract}
SYNOPSIS
The alteration of LDH isozymic patterns was investigated electrophoretically during the maturation of rat ovaries artificially induced by gonadotrophins. In addition, the histochemical distribution of LDH activity was compared with the electrophoretic patterns. While five isozymes of LDH were demonstrated in the ovary of immature rats, isozyme-4 activity was highest. During the induced maturation of ovaries, the activity of isozyme-5 increased while isozyme-1, -2 and -3 activities decreased. On the other hand, the activity of isozyme-4 hardly varied. Histologically speaking, LDH activity was higher in the interstitial and thecal cells than in the granulosa. After formation of luteal bodies, the most intense activity appeared in luteal cells.
\end{abstract}

It is well documented that five isozymic forms of lactate dehydrogenase (LDH; I.I.I. 27) are found in various tissues or organs of mammals (Markert and M $\phi$ ller, 1959; Kaplan et al., 1960; Vesell, 1961; Blanco and Zinkham, 1963; Shaw and Barto, 1963; Vesell and Philip, 1963; Hawkins and Whyley, 1966). Although the isozymic patterns of $\mathrm{LDH}$ are tissue or organ specific, the patterns are generally altered under various physiological conditions (Flexner, et al., 1960; Allen, 1961; Kaplan and Ciotti, 1961; Fine, et al., 1963; Fritz, 1967; Goldberg and Hawtery, 1967). These physiological changes may reflect metabolic transformation of the tissue or organ.

During ovarian maturation, metabolic changes parallel the histological changes. Hence, it is likely that isozymic patterns

Received for publication February 22, 1968.

The following abbreviations have been used: Tris- $\mathrm{HCl}$, tris (hydroxymethyl) aminomethane$\mathrm{HCl}$; Nitro-BT, 2,2'-di-(p-nitrophenyl) -5,5'-diphenyl-3,3'-(3,3'-diethoxy-4,4'-biphenylene) ditetrazolium chloride. of LDH vary during maturation of the ovary as the histochemical distribution of LDH activity changes. However, this problem has not received much attention. This study aims to describe the alteration of $\mathrm{LDH}$ isozymic patterns during the artificial maturation of rat ovary induced by the admnistration of gonadotrophins as well as the histochemical changes of this enzyme activity.

\section{MATERIALS AND METHODS}

Immature female rats of Wistar strain (23-24 day old) were divided into 4 groups; group 1 consisting of the rats to be sacrificed at $24 \mathrm{hrs}$. after subcutaneous injection of pregnant mare serum (PMS), group 2 consisitng of the rats to be treated with PMS and receiving an additional injection of PMS $24 \mathrm{hrs}$. later and killed 48 hrs. after the second injection of PMS, group 3 consisted of the rats receiving the same treatment as in group 2, and administered human chorionic gonadotrophin (HCG) 48 hrs. later and sacrificed 72 hrs. after HCG treatment, and group 4 consisted of the rats given the same treatment as in group 3 receiveing an additional injection 

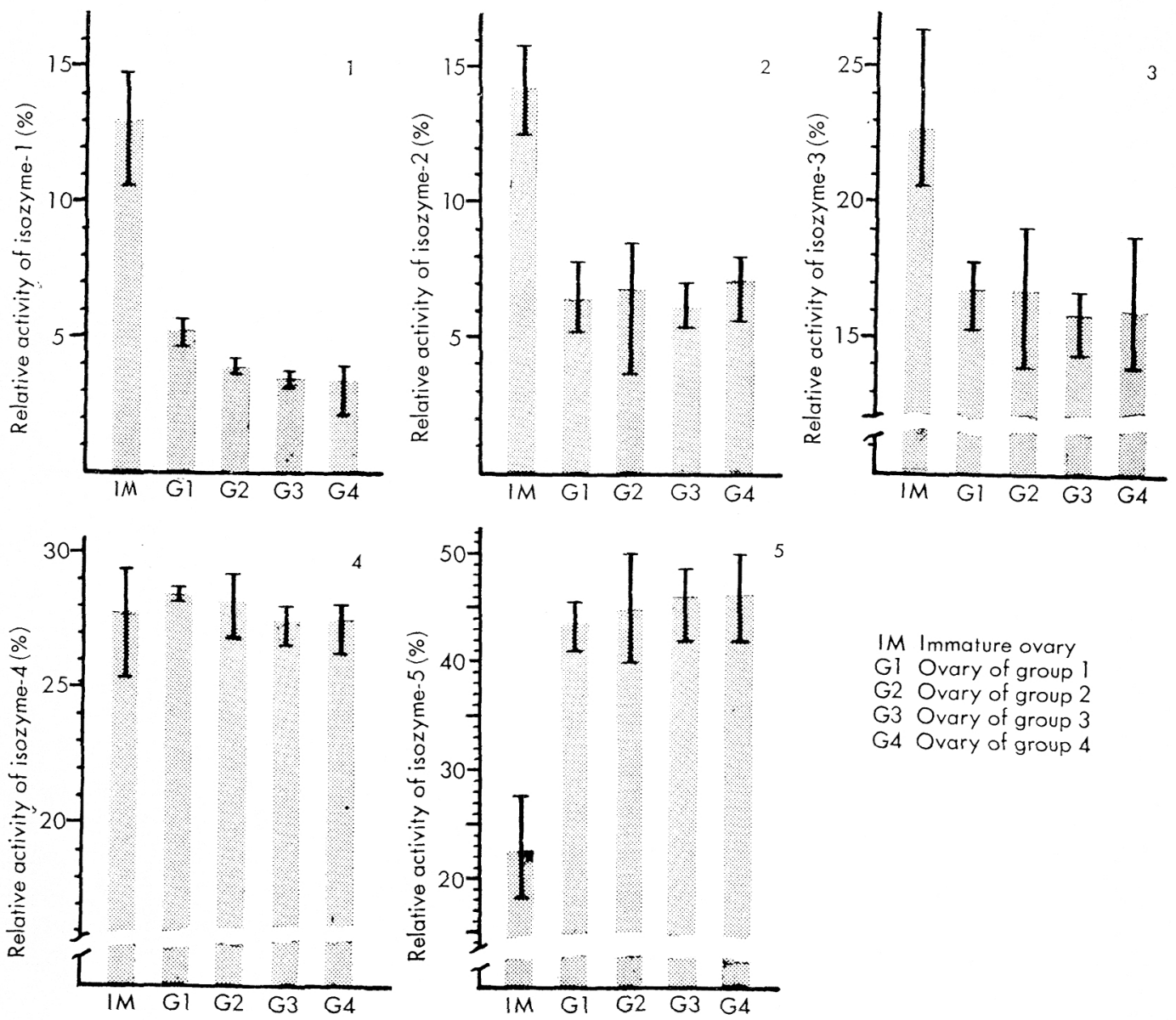

IM Immature ovary
G1 Ovary of group I
G2 Ovary of group 2
G3 Ovary of group 3
G4 Ovary of group 4

Fig. 1. Changes in relative activity of LDH isozyme-1 Fig. 2. isozyme-2

Fig. 3. isozyme-3 Fig. 4. isozyme-4 Fig. 5. isozyme-5

of HCG 72 hrs. later and killed 72 hrs. after the last $\mathrm{HCG}$-treatment. PMS and/or $\mathrm{HCG}$ (Teikoku Hormone Mfg. Co., Ltd.) wasi njected in a single dose at 100 and $50 \mathrm{IU}$, respectively. None-treated immature rats were used as the baseline.

\section{Histochemical study}

Ovarian tissues of the rats were frozen in liquid nitrogen or in acetone refrigerated with solid carbon dioxide (dry ice). Tissue sections $(8 \mu)$ were made by the method previously reported (Takikawa and Matsuzawa, 1967).

The medium for demonstration of the $\mathrm{LDH}$ activity consisted of the following components; $2 \mathrm{ml}$ of sodium lactate $(0.1 \mathrm{M}), 2 \mathrm{ml}$ of Tris- $\mathrm{HCl}$ buffer $(0.1 M, \mathrm{pH} 7.4), 2 \mathrm{ml}$ of Nitro-BT solution $(1 \mathrm{mg} / \mathrm{ml}), 0.6 \mathrm{~m} l$ of NAD solution $(10 \mathrm{mg} / \mathrm{ml})$, $0.3 \mathrm{ml}$ of $\mathrm{NaCN}$ solution $(0.1 M)$ and $2 \mathrm{mg}$ of phenazine methosulfate.

\section{Electrophoretic study}

Thin layers of $5 \%$ polyacrylamide gel were used for the electrophoretic study by the method of Ogita (Ogita, 1965). The gel plate was connected at each end with filter paper strip to a tray containing $0.3 \mathrm{M}$ borate- $\mathrm{NaOH}$ buffer of pH 8.3. 

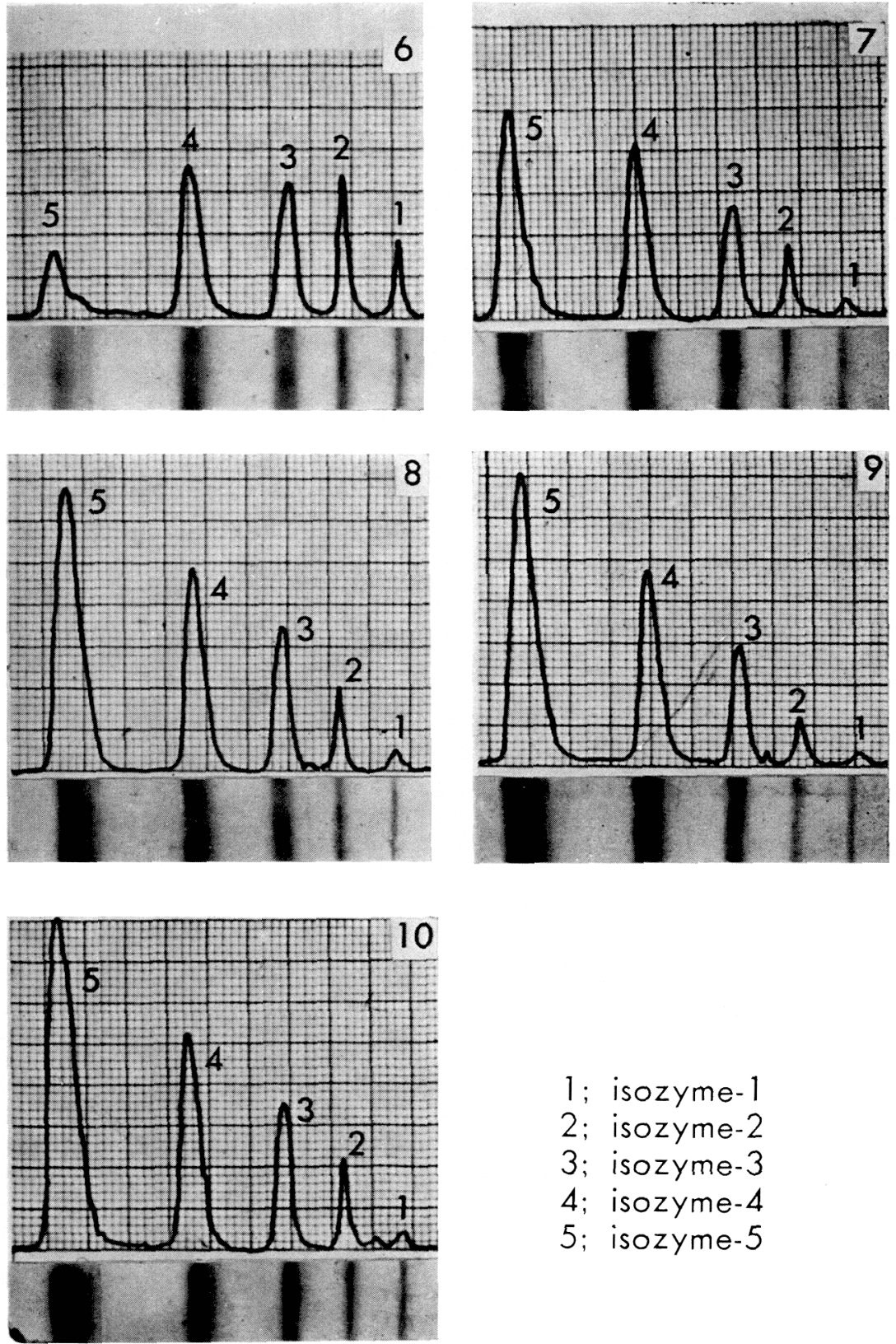

1 ; isozyme-1

2 ; isozyme-2

3 ; isozyme-3

4 ; isozyme-4

5 ; isozyme- 5

Fig. 6. Typical isozymic pattern of LDH. Immature rat Fig. 7. Rat of group 1

Fig. 8. Rat of group 2 Fig. 9. Rat of group 3 Fig. 10. Rat of group 4 
After sectioning with a freezing microtome, the residual block of ovarian tissue was homogenized with 2 volumes of $0.5 \mathrm{~m} M$ EDTA solution at $0^{\circ} \mathrm{C}$. Five $\mu l$ of the homogenate were absorbed with filter paper measuring $10.0 \times$ $1.0 \mathrm{~mm}$ and then placed on the thin layer gel described above for about 45 mins. After removing the filter paper from the gel plate, electrophoresis was carried out at $1.0 \mathrm{~mA}$ per $\mathrm{cm}$ for 1.5-2.0 hrs. at $4^{\circ} \mathrm{C}$. Following electrophoretic migration, the gel was stained with incubating medium for LDH and dired. Optical density of the stained gel film was measured at $500 \mathrm{~m} \mu$ with an automatic recording instrument. The medium for demonstration of $\mathrm{LDH}$ isozymes on the gel was essentially same as used for histochemical demonstration of LDH activity without total volume.

\section{RESULTS}

\section{LDH isozymic patterns}

In electrophoretic study, the activity of $\mathrm{LDH}$ isozymes is presented as relative values. All five forms of LDH isozymes were observed in ovaries of each group, though the patterns varied among these groups.

The activity of $\mathrm{LDH}$ isozyme- 4 was higher in immature rats while isozyme-1 activity was low (Figs. 1-6). During the artificial maturation of the ovary, the activity of isozyme-5 increased continuously (Figs. 5-10). After only 24 hrs. of treatment of PMS, a remarkably high level of isozyme-5 was evident in ovaries of group 1 which were characterized by growing follicles but no luteal body (Fig. 13). In striking contrast, the activity of isozyme-1, -2 and -3 was drastically decreased in group 1 (Figs. 1, 2, 3,6 and 7). The isozyme- 1 activity continued to decrease with maturation. On the other hand, no significant difference was observed in the activity of isozyme-4 during maturation induced by these gonadotrophins (Fig. 4).

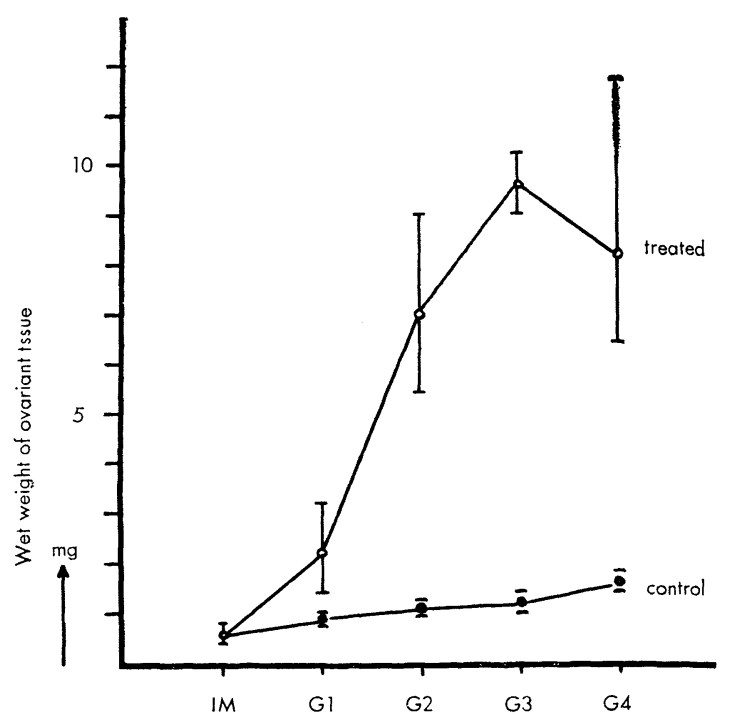

Fig. 11. Changes in wet weight of ovarian tissues during the maturation.

In some cases, there was a slight tendercy for recovery of activity with isozyme-1, -2 and -3 in groups 3 and 4 . Histologically speaking, luteal bodies were obvious in ovaries of groups 3 or 4 (Fig. 14).

It is noteworthy that in the ovaries of group 4 , isozyme- 5 activity was the most intense, whereas the activity of isozyme-1 was in the least (Fig. 10). Moreover, we noted that whenever the activity of isozyme-1, -2 and -3 tended to recover in group 4, isozyme-5 activity decreased.

In the controls, these isozymic patterns did not differ from the pattern in immature rats. However, it was often observed in the controls for groups 3 and 4 that isozyme- 5 activity slightly increased.

\section{Histochemical observation}

Wet weight of ovarian tissues increased with maturation and reached a maximum in group 3 (Fig. 11). In immature ovaries, activity of LDH observed histochemically

Fig. 12. Histochemical activity of LDH in immature ovary. The activity is low in level. $\times 100$

Fig. 13. Ovary of group 1. Interstitial cells show the highest activity of LDH. $\quad \times 40$

Fig. 14. Ovary of group 3. The most intense activity appears in the luteal bodies. $\quad \times 40$

Fig. 15. Ovary of group 2. LDH activity is often strongest in the granulosa cells near the egg. $\times 40$ 

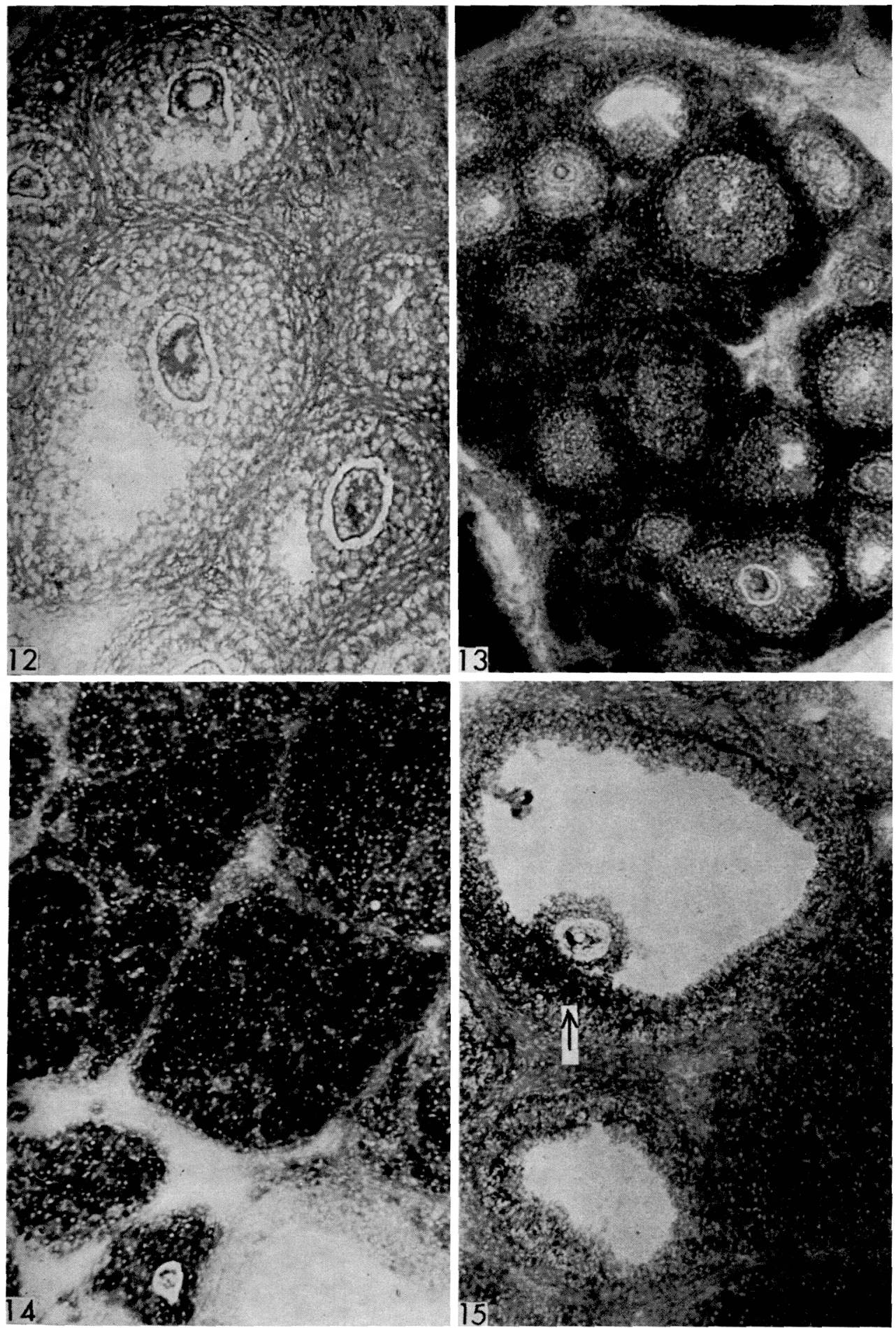
was generally lowest (Fig. 12). However, the cytoplasm of interstitial cells showed slightly higher activity of LDH than did the granulosa cells.

In the rats of group 1 whose ovaries were mainly characterized by many growing follicles but no luteal body, the activity of LDH was increased in granulosa, thecal and interstitial cells when compared with the immature rats. The most intense activity appeared in the interstitial cells (Fig. 13).

In groups 2 and 3, the ovaries were marked histologically by a few luteal bodies and many follicles in various stages of growth. The most intense activity was demonstrated in the cytoplasm of luteal cells while only low activity was apparent in the granulosa (Fig. 14). It was often observed that the granulosa near the egg showed strong LDH activity (Fig. 15). No significant difference in the level of activity was observed between the thecal and interstitial cells.

In the ovaries of group 4, the distribution of LDH activity was similar to that of groups 2 and 3, although luteal bodies increased in number.

\section{DISCUSSION}

It is well known that the activity of LDH isozyme-1 is high in those organs with high aerobic metabolism such as cardiac muscle, while isozyme-5 activity is dominant in skeletal muscle which is characterized by anaerobic metabolism and requires immediate energy (Cahn, et al., 1962; Dawson et al., 1964). In this experiment, the activity of isozyme- 5 increased drastically in the ovaries of group 1 which were stimulated to growth by PMS. On the other hand, isozyme-1 activity decreased. These data suggest that the metabolism of ovary is altered from aerobic to anaerobic type by the administration of PMS. It is possible that in ovarian growth compelled by PMS, energy for growth is occasionally generated in glycolysis. A similar phenomenon was reported by Goodfriend and Kaplan (1964) who showed that estradiol could induce isozyme-5 in uteri of immature rats. Furthermore, Allen reported: in uteri of ovariectomized mice, isozyme-5 activity was increased by estradiol benzoate while isozyme-1, -2 and -3 decreased. In addition, no significant change was observed in isozyme-4 activity (Allen, 1961). This finding is in quite agreement with that obtained in our experiment, although the tissues used were different each other.

It is of interest to note that bovine follicles without fluid showed slight activity of isozyme-5. This suggests that the activity of this isozyme may be minimal in the thecal cells. In addition to this, follicular fluid exhibited less activity of isozyme-5 (Matsuzawa and Takikawa, unpublished data). The histochemical study in this experiment has demonstrated that the increase of LDH activity in ovaries of group 1 treated with PMS occurred particularly in the interstitial cells. Moreover in ovaries of group 1, the activity of isozyme-5 also increased.

In the light of these data indicating that the increased activity of $\mathrm{LDH}$ isozyme-5 parallels the histochemical activity of $\mathrm{LDH}$ in the interstitial cells while the activity of isozyme- 5 is imperceptible in both the thecal cells and the follicular fluid, it is possible to consider that the increase of isozyme- 5 activity in ovaries of group 1 treated with PMS is confined to the interstitial cells. Moreover, isozyme- 5 may be induced by the administration of PMS.

\section{ACKNOWLEDGEMENT}

The authors wish to thank Miss. Y. Sato, Mr. A. Matsui and Mr. K. Mitome for their technical assistance.

\section{REFERENCES}

Allen, J. M. (1961). Ann. N. Y. Acad. Sci. 94, 937. Blanco, A. and W. H. Zinkham (1963). Science 139, 601

Cahn, R. D., N. O. Kaplan, L. Levine and E. Zwilling (1962). Ibid. 136, 962. 
Dawson, D. M., T. L. Goodfriend and N. O. Kaplan (1964). Ibid. 143, 929.

Fine, I. H., N. O. Kaplan and D. Kuftinec (1963). Biochemistry 2, 116.

Flexner, L. G., J. B. Flexner, R. B. Roberts and G. deLa Haba (1960). Develop. Biol 2, 313. Fritz, P. J. (1967). Science 156, 82.

Goldberg, E. and C. Hawtrey (1967). J. Exptl. Zool. 164, 309.

Goodfriend, T. L. and N. O. Kaplan (1964). J. Biol. Chem. 239, 130.

Hawkins, D. F. and G. A. Whyley (1966). Clin. Chim. Acta 13, 713.

Kaplan, N. O., M. M. Ciotti, M. Mamolsky and R. E. Bieber (1960). Science 131, 392.
Kaplan, N. O. and M. M. Ciotti (1961). Ann. N. Y. Acad. Sci. 94, 701.

Matsuzawa, T. and H. Takikawa (1968). Unpublished data.

Markert, C. L. and F. M $\phi 1 l e r$ (1959). Proc. Natl. Acad. Sci. 45, 753.

Ogita, Z. (1965). Metabolism and Disease 2, 67 (in Japanese).

Shaw, C. R. and E. Barto (1963). Proc. Natl. Acad. Sci. 50, 211.

Takikawa, H. and T. Matsuzawa (1967). Endocrinol. Japon. 14, 276.

Vesell, E. S. (1961). Ann. N.Y. Acad. Sci. 94, 877.

Vesell, E. S. and J. Philip (1963). Ibid. 111, 243. 